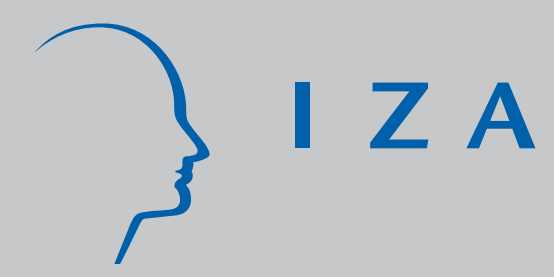

IZA DP No. 1378

The Use of Alternative Work Arrangements by the J obless: Evidence from the CAEAS/CPS

J ohn T. Addison

Christopher J. Surfield

November 2004 


\title{
The Use of Alternative Work Arrangements by the Jobless: Evidence from the CAEAS/CPS
}

\author{
John T. Addison \\ University of South Carolina \\ and IZA Bonn
}

Christopher J. Surfield

Lander University

\section{Discussion Paper No. 1378 \\ November 2004}

\author{
IZA \\ P.O. Box 7240 \\ 53072 Bonn \\ Germany \\ Phone: +49-228-3894-0 \\ Fax: +49-228-3894-180 \\ Email: iza@iza.org
}

\begin{abstract}
Any opinions expressed here are those of the author(s) and not those of the institute. Research disseminated by IZA may include views on policy, but the institute itself takes no institutional policy positions.

The Institute for the Study of Labor (IZA) in Bonn is a local and virtual international research center and a place of communication between science, politics and business. IZA is an independent nonprofit company supported by Deutsche Post World Net. The center is associated with the University of Bonn and offers a stimulating research environment through its research networks, research support, and visitors and doctoral programs. IZA engages in (i) original and internationally competitive research in all fields of labor economics, (ii) development of policy concepts, and (iii) dissemination of research results and concepts to the interested public.
\end{abstract}

IZA Discussion Papers often represent preliminary work and are circulated to encourage discussion. Citation of such a paper should account for its provisional character. A revised version may be available directly from the author. 
IZA Discussion Paper No. 1378

November 2004

\title{
ABSTRACT
}

\section{The Use of Alternative Work Arrangements by the Jobless: Evidence from the CAEAS/CPS}

\begin{abstract}
Alternative work arrangements (AWAs), such as contracting, consulting, and temporary work, have been criticized as providing only atypical, even precarious, employment. Yet they may also allow workers to locate suitable job matches. Exploiting data from all four Contingent and Alternative Employment Arrangement Supplements to the Current Population Survey, we investigate the initial job-finding strategies pursued by the unemployed. Within the narrow window offered by the data, we find that unemployed workers who become reemployed are more likely to find work in AWAs than in regular, open-ended employment. When we evaluate the use of AWAs against unemployment, there is also evidence that the jobless are entering AWAs as pathways out of their initial labor market state.
\end{abstract}

JEL Classification: J21, J24, J63, M50

Keywords: alternative work arrangements, atypical work, temporary work, unemployment, job matching

Corresponding author:

John T. Addison

Department of Economics

Moore School of Business

University of South Carolina

1705 College Street

Columbia, SC 29208

USA.

Email: ecceaddi@moore.sc.edu 


\section{Introduction}

Over the past two decades, there has been an increase in the prevalence of employment arrangements such as consulting, contracting, on-call work, and temporary work in the United States. ${ }^{1}$ This increase has sparked a lively debate concerning the quality of the jobs provided by these alternative work arrangements (AWAs). One key criticism is that they offer less secure and less stable work than open-ended employment (see, for example, the discussion in this Journal by Hylton, 1996; Lee, 1996; Nollen, 1996). Notwithstanding this criticism, AWAs allow the unemployed not only to escape the jobless state but also to gain work experience and even acquire training, attributes that may be expected to improve their subsequent employment prospects.

We examine one aspect of the issue by examining the rates at which unemployed workers enter AWAs and we identify five types of joblessness to allow for the possibility that search behavior is influenced by source of unemployment. We also estimate the relative probability that an unemployed worker will later be observed in an AWA, relative to the rate that we would naturally observe in the labor market. Further, we estimate the unconditional probability that a jobless worker will later engage in AWA employment.

We begin with a barebones review of the literature on the decision to enter AWA employment and the potential of the latter to facilitate open-ended employment. We next discuss the dataset - the recently discontinued Contingent and Alternative Employment Arrangement Supplement (CAEAS) to the Current Population Survey (CPS) - and present some descriptive material on unemployment and unemployment transitions. We then provide our ceteris paribus analysis of the probability of entering an AWA. A brief summary concludes.

\section{Existing Work}

Study of AWAs and their labor market implications is limited. This neglect reflects both a lack of quality data and, until comparatively recently at least, the marginal role that these arrangements have played in the labor market. Past U.S. research using the main source of information on atypical work has followed one of two strands of analysis. The first has focused on the characteristics of AWA workers and jobs (Cohany, 1996; Hipple, 2001; Polivka, 1996a,

\footnotetext{
${ }^{1}$ Estimates of the growth rates in atypical employment vary. For example, Segal and Sullivan (1997) calculate that temporary employment grew by twelve percent annually in the early 1990s. Since the mid-1990s more modest annual growth rates of three to six percent are reported by Surfield (2004) across all forms of flexible employment.
} 
1996b; Surfield, 2004). The second strand is more diverse and covers in addition to the determinants of AWAs (Garen, 1999; Houseman and Polivka, 2000) issues of longer term employment stability that are more clearly related to the present treatment. In particular, in analyzing the responses of workers concerning the employment decision, Morris and Vekker (2001) note that that nearly one-third of all temporary workers indicated that this was the only kind of work they could secure. On the other hand, equal numbers (thirty percent) of temporary workers reported that they chose this type of work either to acquire training and additional labor market experience or as a means of attracting an offer of permanent employment. The remainder seemingly found the scheduling flexibility afforded by temporary employment attractive given the competing demands on their time due to family or personal needs.

More formally, Farber (1999) examines the use of AWA employment as a response to job loss. Specifically, he examines the rates of AWA employment among displaced workers, namely, those losing their jobs by reason of a plant closing, slack work, or the abolition of a position or shift. His results clearly support use of AWA employment as a means for (displaced) workers to acquire at least a degree of employment continuity either through the direct conversion of temporary into regular work or by increasing the individual's employability. Farber's probit analysis suggests that displaced workers are significantly more likely than their non-displaced counterparts to be holding AWA employment, but also that the probability of selecting this type of work is decreasing in the time that has elapsed since the displacement event. Workers who were displaced three years before were less likely to be observed in an AWA than those who had been displaced one year before; and after four years there was no measurable difference in AWA job-holding as between displaced workers and those who were never displaced.

Farber only includes the reemployed (among the ranks of the displaced and nondisplaced) in his analysis. If unemployment persistence has a greater half life than that of an alternative employment arrangement, and if exit from the labor force does not indicate an optimal timing phenomenon but instead discouragement, his convergence process may be more apparent than real. In any event, given the much shorter intervals captured in the present treatment we must also allow for unemployment persistence.

III. Data 
The CAEAS was added to the Current Population Survey in February 1995 to facilitate study of AWAs. It provides information on a wider range of alternative work forms than is available in other nationally representative samples, and its large scale is a further advantage. Like its betterknown counterpart, the Displaced Worker Survey (DWS), the CAEAS is administered biennially, in February of odd years. Unlike the DWS, however, it was discontinued after February 2001. As with other supplements, the data on work arrangements in the CAEAS can be combined with detailed demographic and human capital information on the respondent contained in the parent CPS.

The CAEAS is not a true longitudinal dataset, so that we cannot directly address the issue of whether AWAs serve as stepping stones to regular employment. Indeed, we can only identify the work arrangement of an individual in February of odd years, namely, 1995, 1997, 1999, and 2001, by which time all individuals have been rotated out of the parent survey. As a result, the best we can do is examine transitions into AWAs from unemployment over the narrow window of a month, by matching individuals from the February CAEAS with the January CPS. ${ }^{2}$ Using these two surveys, we create four one-month samples for each year the CAEAS was administered. Since there is no overlap of individuals across the samples, we pool the data.

Following BLS conventions, jobless individuals actively seeking employment are initially classified into one of five exclusive unemployment categories. The first category is job losers, namely, individuals who are jobless as a result of employer dissolution of the match, with or without cause. The next two groups comprise those individuals whose temporary job ended and job leavers. New entrants and reentrants make up the remaining categories of unemployed individuals. Our analysis will also exploit a further group of individuals from the January CPS, namely the initially employed. Note the CPS is silent as to the type of employment held by these workers.

There are eight possible ways classifying individuals as of end period (i.e., February in each of the four years). In addition to being unemployed or moving out of the labor force, there are five different types of AWA employment plus regular work, which category comprises all

\footnotetext{
${ }^{2}$ For additional discussion on the design of the CPS and the matching of individuals across the surveys, see the Data Appendix. One caveat concerning the use of the 2001 CAEAS needs to be made. Due to a BLS programming error, the outgoing rotations of the CPS were not administered the supplement. Necessarily, these individuals were omitted from our analysis
} 
those employed individuals who do not identify themselves as being engaged in an alternative work arrangement. The five AWAs are:

(i) agency temporaries - workers who rely on a temporary help service to secure their job-tasks, or who receive their paycheck from a temporary help service. The latter condition inevitably entails the inclusion of some personnel who have regular, open-ended employment with the agency, although Houseman and Polivka (2000) point out that such employees constitute only 3.2 percent of an agency's total employment.

(ii) direct-hire temporaries - temporary workers who provide their services directly to the paycheck-issuing entity. This category also includes workers who indicate that they are hired directly by the client firm to fill a temporary position, complete a specific project, or substitute for an absent or vacationing employee. Direct-hires are those hired by a firm for only a fixed period of time, or into jobs that are seasonal in nature; (iii) on-call workers - those who work for a firm on a per-diem or as-needed basis, including day laborers;

(iv) contract workers - those who rely on a third party to provide clients or projects. As is conventional, we also impose the restrictions that a contract worker needs only to have one client and usually works at that client's workplace;

(v) contractors/consultants - self-employed contractors and consultants who are responsible for acquiring clients or projects.

We examine the use of AWAs by the jobless between January and February of the same year. Although this is a short interval, those observed as unemployed in January may have been looking for employment for considerably more than a month. Continued unemployment may prejudice nonstandard forms of employment as well as regular employment. Alternatively, longer duration might lead such individuals disproportionately into AWAs as employment-oflast-resort. Our use of elapsed duration allows us to address these issues. Note that there is no correspondence between our use of elapsed duration and Farber's (1999) construct of time since displacement. Farber is looking at re-employment throughout and seeking to determine whether the tendency for displaced workers to locate jobs in atypical work arrangements changes over (what is likely to be) the reemployment interval. If anything Farber could be (crudely) characterized as examining the consequences of on the job search. 
Finally, in constructing our sample we excluded those individuals for whom we lack the requisite AWA or demographic and human capital data (age, education, ethnicity, gender, marital status, region, and urban residence). On grounds of their likely very different attachment to the labor force, we also excluded those individuals aged above 65 years and below twenty years: The same restrictions imposed by Farber.

\section{Descriptive Statistics}

The five sources of joblessness are identified in Table 1. Involuntary job loss and labor market reentry emerge as the chief causes of unemployment, and together account for more than three quarters of the total. Given the relatively small number of observations in the individual onemonth samples, most of the ensuing discussion centers on the pooled sample.

The February labor market status of those unemployed in January is charted in Table 2. Not surprisingly, unemployment is highly persistent: Nearly one-half of those observed as being unemployed in January remain so in February. Exiting the labor force also appears to be an important transition: One-fifth of the unemployed follow this route. Of those who found employment, regular work is the main form of work selected.

In terms of AWAs, the main question is whether or not the jobless are more or less prone to take such jobs than the typical worker? To help address this issue we include in the cross tabulations of Table 3 those initially employed in January. First, note that although agency temping garners much popular attention, it accounts for less than one percent of overall U.S. employment. That said, it is seemingly an important source of reemployment for those whose joblessness stemmed from an earlier temporary job having ended. Such individuals are almost four times as likely as the typical employee to be agency temporaries. In fact, all categories of the unemployed are more likely than other workers to be agency temporaries. Similar results with the exception of new entrants - are found for direct-hire temporary workers. However, across all five sources of joblessness, contracting/consulting work is significantly less likely to be undertaken by those unemployed in January vis-à-vis those initially holding employment. For its part, contract work per se evidently plays a minor role for both populations, and in the balance of this analysis will be combined with the more numerous category of contractors/consultants category.

While confirming the persistence of unemployment noted earlier, the data in Table 3 also 
indicate that job leavers are the most likely subsequently to be employed in regular or openended employment and, ignoring reentrants and entrants, the least likely to be unemployed. Although these results are expected - presumably on the grounds of superior labor market information - the differences between job leavers and losers are muted.

\section{Multinomial Analysis}

Although the cross tabulations are suggestive, we have to take into consideration the (observed) differences in the characteristics of individuals in the two populations of the initially employed and unemployed in January of each of the four years. ${ }^{3}$ To this end, we estimate a multinomial choice model, otherwise known as a multinomial logit. Ceteris paribus, the multinomial logit provides estimates of the probability of observing an individual possessing a particular characteristic in an outcome relative to the probability of a reference characteristic being observed in the outcome. For example, we can examine how much more or less likely a worker made jobless due to an involuntary separation from the employer is to select employment in an AWA than one who held employment in January.

For consistency across our two empirical models, we take those initially employed in January as the reference category. The goal is to determine whether or not the unemployed strictly, those in each unemployment category - opt for employment in an AWA at a rate that is greater than obtains for the average worker. We provide two sets of estimates: the first is for the full sample outlined in section IV, namely, those who were initially employed/unemployed in January and either employed or unemployed/out of the labor force in February; the second is for the sub-sample of individuals who had obtained or who were in employment in February. We first use unemployment as our reference outcome to directly gauge the use of AWAs as an escape from joblessness. Next, in line with Farber, we use regular work as the reference outcome and exclude the still unemployed (and economically inactive) from the sample. We note parenthetically that because of the small numbers engaged in contract work we amalgamate this category with contractors/consultants, and label the combination contracting/consulting.

Table 4 presents the results obtained from the model that uses employment in January as the reference characteristic and unemployment in February as the reference outcome. The coefficient estimates reflect the probability that those jobless in January will find employment of

\footnotetext{
${ }^{3}$ Weighted summary statistics for the pooled sample can be obtained from the authors on request.
} 
some kind rather than continuing in unemployment when compared with their counterparts among the initially employed. We take the rates at which the initially employed are observed in the various outcomes to approximate the distribution of the work forms naturally found in the labor market. Accordingly, a positive (negative) coefficient estimate indicates that a particular source of unemployment increases (decreases) the likelihood that an individual will later be observed in AWA employment when compared with both the likelihood of being unemployed and the rates observed for the general workforce.

The results given in Table 4 reveal that all those jobless in January are less likely to hold AWA employment relative to being unemployed when we compare them to the initially employed. ${ }^{4}$ This is hardly surprising: As noted in section IV, unemployment is the dominant outcome experienced by the jobless. Furthermore, we are comparing the (February) unemployment rates of the jobless against the very small fraction of those holding employment in January who become jobless after a month.

We observe some modest attenuation in the (negative) coefficient estimates after we take into consideration the length of a worker's unemployment spell. Across all employment outcomes - the four AWAs - we find a slight reduction in how much less likely it is that an unemployed worker will be holding employment of some kind relative to continued joblessness. For its part, time spent unemployed is highly significant: Each additional month's joblessness decreases the likelihood that a worker will be observed in any outcome other than unemployment. Indeed, the positive coefficient estimate for the quadratic term in elapsed duration indicates that this reduction in the relative probability intensifies with the time spent unemployed.

Despite the jobless being less likely to be observed in an AWA when we compare them with the initially employed, they should not be construed as shunning AWAs. When we examine the estimates of the unconditional probability that the unemployed will be observed in an AWA, note the positive signs of these marginal effects. That is, unemployment holds positive implications for the (absolute) probability of a worker entering into AWA employment. In particular, unemployment has the largest impact on the likelihood of a worker being observed as holding employment either as a direct-hire temp or as an on-call worker. A worker who was

\footnotetext{
${ }^{4}$ The coefficient estimates do not offer a quantitative statement of just how much less likely a particular type of job loser is to be observed in a particular outcome than are the initially employed. Such an inference can be drawn if we calculate the inverse Mills ratio.
} 
unemployed in January is two to five percentage points more likely to hold a direct-hire temp position in February. Unemployment increases the probability that a worker will be engaged in on-call work in the range of one and a half to three percentage points. Both of these increases are quite substantial, given that only four and one percent of the general workforce is respectively employed in these two AWAs.

Although smaller in magnitude, there is also a positive relationship between unemployment and the likelihood of later securing employment as an agency temp: The probability that such workers will hold this type of employment is increased by about one to two percentage points. Although this effect seems small, keep in mind that less than one percent of workers receive their paychecks from a temporary agency. Other than in the case of voluntary separations, being unemployed also elevates the probability of a worker later being in a contracting/consulting position. This increase is in the range of one to five percentage points, whereas voluntarily leaving one's employer reduces by about two percentage points the likelihood of later being observed in this work form. The overall increases in the rates at which the unemployed enter into AWAs, however, pale in comparison to the probability that these workers will be unemployed over the narrow period of time covered by this analysis.

Table 5 presents estimates that are predicated on all those unemployed in January finding employment. We have only five outcomes with the backward excision of the unemployed and economically inactive in February from the base population samples in January. To reiterate, we are comparing the outcomes realized by the jobless who successfully gained employment with the experience of the general workforce who were employed in both January and February. The coefficient estimates reported in the Table 5 indicate the effect that each regressor has on the probability of an unemployed individual subsequently becoming employed in one of the four different AWAs relative to the probability of observing that individual in open-ended employment. The values in brackets are again the marginal effects.

The material in Table 5 provides a large measure of support for Farber's first-level finding that the jobless (in his case, displaced workers) are more likely to locate employment in an AWA than the average worker. Looking at the results in more detail, it is evident that, with one exception, jobless workers are relatively more likely to find work in an AWA than in openended employment. The exception is the job leavers-contracting/consulting pair: Compared with those in employment in January, job leavers are no more likely to be observed in contracting- 
consulting activities than in regular employment. Also, the positive coefficient estimate for new entrants is poorly determined in respect of the outcome categories of agency and direct-hire temporary employment. Otherwise, irrespective of the source of their unemployment, the jobless find work in AWAs at rates that exceed the representation of such jobs in the economy. As far as the impact of elapsed jobless duration in January is concerned, there is little to suggest that it materially affects the probability of locating an AWA versus regular employment. This is not unexpected because, as previously noted, the main effect of the search is prolonging unemployment.

\section{Concluding Remarks}

For those who successfully secured an offer of employment, AWAs seem to be disproportionately used by jobless workers transitioning back into employment. If we further argue that the current distribution of jobs is the "norm," it follows that this central tendency is only achieved after those seeking regular work spend some time in (perhaps a sequence of) such arrangements alongside those for whom atypical work is for a variety of reasons their first choice. AWAs are thus in part a stepping stone into regular employment - even if the majority of re-employed individuals eventually find regular employment - providing employers with either a direct or indirect screen. This result was first reported by Farber for a sample of displaced workers. Inferentially, we find it applies to all sources of unemployment, not just displacement.

These results are obtained for those who are in employment. But the jobless in January are less likely to be observed in an AWA in February than they are to be searching for employment. Yet the narrow window offered by the data means that we should resist the interpretation (of the reduction in relative probabilities) that AWAs fail to represent viable pathways out of unemployment. That is to say, we still find that unemployment raises the unconditional probability of a worker selecting AWA employment. These increases are also quite substantial in size when compared with the current distribution of jobs. Accordingly the estimated relative probabilities merely suggest that we are not likely to see significant movement out of unemployment within a period of one month. By the same token, it is equally clear that research focusing on the longer-term implications of AWAs for employment continuity is in order. 


\section{REFERENCES}

Cohany, Sharon R. "Workers in Alternative Employment Arrangements." Monthly Labor Review 119 (October 1996): 31-45.

Farber, Henry S. "Alternative and Part-Time Employment Arrangements as a Response to Job Loss.” Journal of Labor Economics 17 (October 1999): S142-69.

Garen, John. "The Partial De-Integration of Work Through the Use of Temporary Agency and Contract Workers." Paper presented at the $69^{\text {th }}$ Annual Meeting of the Southern Economic Association Meetings, November 1999.

Hipple, Steven. "Contingent Work in the Late-1990s." Monthly Labor Review 124 (March 2001): 3-28.

Houseman, Susan N. and Anne E. Polivka. "The Implications of Flexible Staffing Arrangements for Job Security." In David Neumark, ed. On the Job: Is Long-Term Employment a Thing of the Past? New York: Russell Sage Foundation, 2000, pp. 427-62.

Hylton, Maria O'Brien. "Legal and Policy Implications of the Flexible Employment Relationship.” Journal of Labor Research 17 (Fall 1996): 583-93.

Lee, Dwight R. “Why Is Flexible Employment Increasing?” Journal of Labor Research 17 (Fall 1996): 543-53.

Madrian, Brigitte C. and Lars John Lefgren. "A Note on Longitudinally Matching Current Population Survey (CPS) Respondents." National Bureau of Economic Research Technical Working Paper 247, November 1999.

Morris, Michael D. S. and Alexander Vekker. "An Alternative Look at Temporary Workers, Their Choices, and the Growth in Temporary Employment." Journal of Labor Research 22 (Spring 2001): 373-90.

Nollen, Stanley D. "Negative Aspects of Temporary Employment." Journal of Labor Research 17 (Fall 1996): 567-82.

Polivka, Anne E. "A Profile of Contingent Workers." Monthly Labor Review 119 (October 1996a): 10-21.

. "Into Contingent and Alternative Employment: By Choice?" Monthly Labor Review 119 (October 1996b): 55-74.

. "Data Watch: the Redesigned Current Population Survey." Journal of Economic Perspectives 10 (Summer 1996c): 169-80. 
Segal, Lewis M. and Daniel G. Sullivan. "The Growth of Temporary Services Work." Journal of Economic Perspectives 11 (Spring 1997): 117 - 36.

Surfield, Christopher J. "The Contingent Workforce." Economics and Economic Education Research Journal, forthcoming 2004. 
Table 1

Causes of Joblessness in January of Each Year

(in percent)

\begin{tabular}{lccccc}
\hline & 1995 & 1997 & 1999 & 2001 & Pooled \\
\hline Job losers & $47.8 \%$ & $44.4 \%$ & $48.3 \%$ & $46.0 \%$ & $46.5 \%$ \\
Temporary job ended & 9.6 & 11.6 & 10.2 & 11.9 & 10.8 \\
Job leavers & 8.9 & 11.8 & 11.7 & 12.5 & 11.1 \\
New entrants & 2.9 & 2.8 & 3.0 & 4.3 & 3.2 \\
Reentrants & 30.8 & 29.3 & 26.7 & 25.4 & 28.4 \\
& & & & & \\
$n$ & 1,964 & 1,936 & 1,537 & 973 & 6,410 \\
\hline
\end{tabular}

Note: Columns may not sum to $100 \%$ due to rounding errors.

Table 2

Labor Market Outcomes of the Jobless One Month Later, February of Each Year (in percent)

\begin{tabular}{lccccc}
\hline & 1995 & 1997 & 1999 & 2001 & Pooled \\
\hline Regular workers & $18.4 \%$ & $18.4 \%$ & $22.0 \%$ & $23.7 \%$ & $20.2 \%$ \\
Agency temporaries & 1.7 & 1.7 & 1.1 & 1.6 & 1.5 \\
Direct-hire temporaries & 5.8 & 4.6 & 4.7 & 5.7 & 5.1 \\
On-call workers & 3.4 & 2.6 & 2.5 & 3.2 & 2.9 \\
Contract workers & 0.5 & 0.3 & 0.2 & 0.0 & 0.3 \\
Contractors/consultants & 2.2 & 2.2 & 1.7 & 2.1 & 2.0 \\
Unemployed & 49.3 & 52.7 & 48.4 & 46.5 & 49.7 \\
Out of labor force & 21.5 & 19.0 & 20.6 & 19.3 & 20.1 \\
& & & & & \\
$n$ & 1,964 & 1,936 & 1,537 & 973 & 6,410 \\
\hline
\end{tabular}

Note: See Table 1. 
Table 3

Employment Outcomes One Month Later by Employment Status in January, Pooled Sample (in percent)

\begin{tabular}{lcccccc}
\hline & $\begin{array}{c}\text { Initially } \\
\text { employed }\end{array}$ & $\begin{array}{c}\text { Job } \\
\text { losers }\end{array}$ & $\begin{array}{c}\text { Temporary } \\
\text { job ended }\end{array}$ & $\begin{array}{c}\text { Job } \\
\text { leavers }\end{array}$ & $\begin{array}{c}\text { New } \\
\text { entrants }\end{array}$ & Reentrants \\
\hline Regular work & $85.8 \%$ & $23.0 \%$ & $14.9 \%$ & $24.8 \%$ & $15.1 \%$ & $16.4 \%$ \\
Agency temporaries & 0.7 & 1.2 & 2.6 & 1.9 & 0.8 & 1.6 \\
Direct-hire temporaries & 4.2 & 5.1 & 7.0 & 4.3 & 3.5 & 5.0 \\
On-call workers & 1.1 & 3.3 & 3.7 & 1.4 & 0.9 & 2.8 \\
Contract work & 0.4 & 0.4 & 0.3 & 0.2 & 0.5 & 0.2 \\
Contractors/consultants & 5.5 & 2.6 & 2.8 & 1.1 & 1.6 & 1.2 \\
Unemployed & 1.1 & 53.2 & 53.7 & 47.7 & 41.1 & 44.1 \\
Out of labor force & 1.7 & 13.5 & 17.9 & 19.6 & 37.7 & 30.0 \\
& & & & & & \\
$n$ & 126,924 & 3,058 & 692 & 708 & 176 & 1,776 \\
\hline
\end{tabular}

Note: See Table 1. 


\section{DATA APPENDIX}

Although our analysis exploits (combinations of) only two points of time in the CPS data, it is possible to follow the households included in the CPS for a maximum of 16 months. Households are actively interviewed for four months, rotated out for an eight-month period, and reinterviewed for a final four months prior to being permanently rotated out of the CPS. However, only those households actively interviewed in both January and February of odd years are eligible for inclusion in the four samples used to analyze the employment outcomes of the jobless. In addition, given the rotational design of the CPS, we exclude the cohort of individuals exiting (entering) the CPS in January (February) from these samples.

In matching data from the February CAEAS to the parent CPS for January, one key concern is that the interviewing unit is the household, not its residents. Unlike other truly longitudinal surveys, such as the National Longitudinal Survey of Youth or the Panel Study of Income Dynamics, the CPS does not re-interview individuals who switch residences. Nonetheless, individuals remaining in CPS households one month later may be identified by using a combination of the household identifier (HRHHID), the individual line number (LINENO), and the household number (HUHHNUM). We use Madrian and Lefgren's (1999) matching algorithm to identify individuals across the two CPS surveys. As cautioned by these authors, however, the three identifiers may not necessarily uniquely identify individuals over time. Given this concern, additional constraints are imposed on the match algorithm to ensure that we include only valid matches in our cohort samples

Ideally, the additional matching variables should be characteristics that are timeinvariant. We thus reject as invalid matches in which the reported gender or ethnicity changes from one month to the next. One additional variable is included in our matching algorithm: Presumably, an individual's age should be identical in each of the months examined or, at most, should increase by one year. We therefore reject as invalid those matches where an individual's age increases in excess of one year from January to February.

Given that the CPS uses households as the primary interviewing unit, a bias may be introduced into the data if our match rates for the jobless are substantially different from what would be observed naturally in the data. Specifically, our concern is that jobless individuals whom we cannot identify later in the CPS data moved to take advantage of better labor market opportunities than are available to them at their initial residence. In other words, unobserved 
heterogeneity may be a cause for concern. To test for this possibility, the table below gives match rates for the four different samples extracted from the CPS. As noted at the outset, we are in principle only able to match a maximum of seventy-five percent of the households contained in the January CPS to those contained in the subsequent February CAEAS. Accordingly, the match rates presented are reported as a percentage of this total. In keeping with the convention established herein, we use the match rates for those who are employed in January as representative of the rate we would naturally observe in the CPS data. The motivation for this selection is that employed persons (in January) are less likely to attrit by reason of searching for better labor market opportunities than are unemployed persons (in the same month). Individuals who held employment in January and whom we cannot identify one month later in the data thus approximate the attrition rate that would normally be found in the CPS.

Of those individuals that we can in principle match, we observe some significant differences in the match rates across the various initial January labor market states. Relative to those who held employment in January, the jobless are in general significantly less likely to be in the same household, and therefore also the CPS, one month later. The biggest slippage seems to be for reentrants in general and for the 2001 cross section in particular. Interestingly, we observe those who voluntarily separated from their former employer (i.e., job leavers) appear to be less likely to remain in the CPS than those who were already employed. Possibly these jobless workers left their former employer because of a more suitable offer of employment not available in their area. Given the noted differences in the match rates, there is a degree of concern about our ability to generalize our results. To be more precise, if the lower match rates are due to the unemployed moving location to acquire employment, we might be underestimating the reemployment rates of the jobless as a whole.

Note that the match rates for the 1995 sample are substantially lower across all of the initial January labor market states relative to those of the three subsequent cross-sections. This discrepancy is easily reconciled given the implementation of several changes in the design of the CPS noted by Polivka (1996c). Prior to 1996, interviews were conducted using paper interviewing forms, with the twelve-digit HRHHID transcribed from the master file onto the monthly survey by hand. Computer-assisted interviewing methods after 1995 reduced transcription errors between interviews and the master file. In September 1995, the household identifier was further refined to allow for more precise matching of individuals across CPS 
surveys. The matching algorithm used for both 1995 samples are identical to that used to construct the other six samples.

CPS Match Rates, Percent

\begin{tabular}{lllll}
\hline & 1995 & 1997 & 1999 & 2001 \\
\hline Initially employed & $64.3 \%$ & 85.0 & 84.9 & 87.3 \\
Job losers & 63.5 & 82.4 & 83.9 & $84.8^{*}$ \\
Temp job ended & 61.4 & 84.6 & 80.9 & $81.6^{* *}$ \\
Job leavers & 60.3 & 86.2 & 82.4 & $77.8^{* * *}$ \\
New entrants & 58.8 & 87.9 & 88.4 & $82.2^{* * *}$ \\
Reentrants & 62.8 & $81.4^{* * *}$ & $82.0^{*}$ & $81.6^{* * *}$ \\
\hline
\end{tabular}

Note: $* * *, * *, *$ indicate that the match rates calculated for the various sources of joblessness are significantly different from the match rates obtained for those initially employed in January at the $.01, .05$, and .10 levels, respectively, paired $t$-test. 